\title{
Rubrics: The Key To Fairness In Performance Based Assessments
}

Carol M. Shepherd, National University, USA

Ann Mary Mullane, Essex County College, USA

\begin{abstract}
Life involves a myriad of skills. Most of the basic skills are undeniably 'classics' such as communication and problem solving. The interpretation and delivery of these skills has morphed into a complicated science, with the changing social environment and the growing prevalence of technology in our everyday existences. Commonplace technology, as evidenced through word processing, spreadsheets and presentation programs support Gardner's 1980's proposition of multiple intelligences. Furthermore, the inclusion in many K-12 curricula of courses such as web design and the acceptance of PowerPoint as a presentation enhancement, forces the classroom teacher not only to accept Gardner's concepts but also creates a worrisome quandary of authentic assessment development, implementation and evaluation. Institutions of higher education must prepare their teacher candidates to effectively deal with this new form of assessment. Teachers are confronted with the theme of man versus machine anew. Refined methods of evaluation are needed to assess not only the learning of the student in the traditional sense but also the manipulation of technology as a presentation vehicle. Much of the existing technology has developed so quickly that certain 'project enhancers' while pleasant and fun, are not evidence of a deeper understanding of the subject matter but simply a distraction. Performance based assessments, while enabling students to express their mastery of content according to their learning styles and skill strengths, are difficult to score objectively and fairly. A rubric is a common scoring guide frequently used in the attempt to fairly assess creative work. It is necessary to have a taxonomy of the levels of talent, or creativity, in the grading process. Unfortunately, teachers are more willing than they are able to accurately and dispassionately assess the projects that they want their students to explore, such as posters, skits or plays, PowerPoint presentations, websites and videos. This study will address the necessity to balance students' creative efforts with the reality of deadlines, the conventions of their chosen medium and the ability to self-assess their own efforts without the benefit of traditional proofreading. The proposed methodology will be a search of the literature in addition to action research. The expected outcomes will be a sharing of rubrics and guidelines to assist educators in fairly and objectively coping with authentic assessment development, implementation and evaluation. This information will be valuable in training teacher candidates to effectively and fairly deal with performance based assessments.
\end{abstract}

Keywords: rubrics, performance based assessment

\section{INTRODUCTION}

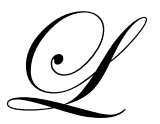

ife involves a myriad of skills. Most of the basic skills are undeniably classics such as communication and problem solving. The interpretation and delivery of these skills has morphed into a complicated science, with the changing social environment and the growing prevalence of technology in our every day existences. Pre-school children have a changed sensibility of their environment and learning strategies even though kindergarten at age five is regarded as the traditional beginning of formal education. It is not uncommon for pre-school children to competently operate a VCR or DVD player and recognize by the picture on the container the 
movie of their choice. In the progressive day care center the traditional "circle time" discusses not only the weather but also the rudimentary characteristics of a painting by Monet.

As the theory of multiple intelligences (MI) comes of age Gardener remains intrigued by the interest and the interpretation of his work. The educational community accepted Gardner's position negating "intelligence as a single capacity" (November, 1995, p.2). However, successfully incorporating MI theory into the curriculum and the classroom has been uneven, cumbersome and sometimes downright ludicrous. Many educators want all curricula to fulfill all aspects of MI theory. However, the essence of MI theory is the antithesis of a 'one size fits all' education.

MI theory is only one of the many concepts that have impacted education in the last two decades. While federal legislation for inclusive education for all students through Individuals with Disabilities Education Act (IDEA) and, more recently, the accountability mandated by No Child Left Behind (NCLB) confounds school administrators, technology has become commonplace in the classroom. Basic computing tools, such as word processing, spreadsheets and presentation programs, have become part of the daily diet of teachers and students alike. Web Design classes and the acceptance of PowerPoint as a presentation enhancement force the classroom teacher not only to embrace Gardner's MI theory that intelligence is evident in various capacities, but also creates a worrisome quandary of authentic assessment development, implementation and evaluation (December, 1995).

Teachers are confronted with the theme of man versus machine anew. Although there has been technology funding on all levels of government and special interest groups, Susan Patrick, Director of Educational Technology, US Department of Education states that, "despite a decade of significant technology investment, most achievement indicators are flat" (Jancich). Successful schools are measured by student achievement, especially in this reign of NCLB. As school funding shrinks, both administrators and community question the value of an educational component that requires a constant drain of funds. Technological competence for teachers, which is measured by a growing number of K-12 districts, needs to go beyond the drill and practice exercises and the electronic gradebook. Reich notes that true expertise will build $21^{\text {st }}$ Century Work Skills of abstraction, systematic thinking, experimentation and collaboration (Jancich). The high school curriculum has grown in response to the needs and desires of the community, but it is both the lesson delivery system and the assessment mechanism that are weak. The various advanced placement classes that are routinely part of the millennium high school curriculum, as well as technology based classes, such as web design, strain the traditionally rigid assessment process. It is vital that institutions of higher education prepare their teacher candidates to deal with this rather new development in student evaluation.

In American schools, the emphasis has been on teaching students about computers and teaching the skills necessary to use them. As a result, computers are the subjects of instruction. This instruction and usage are in isolation, in preparation for future utility. Skills in manipulating telecommunications and multimedia are taught, to be eventually used in other school subjects and in the outside world (Becker, 1993). There is a lack of using computers in non-computer classes. Secondary schools are behind in curriculum development for implementing computer-based tools in classes teaching subject matter. The problem is that most subject matter teachers do not know how to implement technology in their classes. They do not know how to relate multimedia to history, fine arts, English, and other subjects. There is a need for curriculum upgrading in the academic disciplines, in order to make computer education meaningful in schools (Becker, 1993). Although Becker's article was written over ten years ago, it is still true today. Changes have been made to curricula, but these changes have been superficial compared to the possibilities.

NCLB legislation has increased the emphasis on high stakes testing as a means of improving instruction. The accountability standards of NCLB have caused some states to review their assessment measures. Maryland eliminated the long standing Maryland School Performance Assessment Program (MSPAP). Maryland students in grades 3,5 , and 8 would respond to interdisciplinary tasks that required the application of skills and knowledge to real-life problems in favor of an off-the-shelf multiple-choice test. The adjustment was made solely for the purpose of adhering to the current federal regulations. Performance based assessments, while enabling students to express their mastery of content according to their learning styles and skill strengths are difficult to score objectively and have only a vague relationship to MI theory. Some teachers are concerned about the objectivity of alternative 
assessment methods while others question the authenticity and reliability. Those in school administration prefer the simplicity of the rigid pen and paper final exam tradition.

It is a daunting task to objectively and fairly evaluate artistic and multimedia projects. The assessment tool needs to balance the creativity and artistic ability of the student with the standards and theory of the demonstrated medium. It is difficult to assess what a student has learned in making a video or creating a website, for example. In the book, Evaluating Creativity, by Julian Sefton-Green and Rebecca Sinker (2000), the authors have collected essays from teachers and researchers in England which deal with the issues of evaluating artistic and media projects. The authors suggest that through these evaluations, there will be an improvement in the growth and insight of both students and their parents.

A common method of performance assessment is the rubric. "A rubric describes levels of quality, usually on a point scale" (Berry, 1997). Defining quality for both the teacher and the student is a primary goal of using a rubric for assessment. While the rubric reflects both the nature of the project and the grade level of the pupil, it helps students develop a sense of responsibility for their own work because the rubric focuses the students' attention to the elements of the assessment process. In varying degrees, many teachers, in order to be fair and objective, mentally engage in a rubric-like process, especially when grading essays or PowerPoint presentations. The difference between the teacher's mental process and a rubric is fundamental. A good rubric is normed with the content standards for the class. The accomplishment is graded against the lesson standards. However, there exists the effort-based grade, where a child moves on because emotionally the teacher senses an effort, but not necessarily a tangible achievement. This clear divide between accomplishment and effort provides clarity for the teacher in justifying to the student and/or parent as to why the grade is what it is. In a society that is becoming more and more litigation-minded, the time consuming process of developing an authentic rubric with a clear goal and purpose for student assignments is worth the energy.

Rubrics are increasingly being used in higher education and $\mathrm{K}-12$ education settings (Mitchell, 2006). Scoring rubrics can be created for a variety of subjects and situations. They can measure knowledge, skill, effort, and work habits. They provide a qualitative description of performance criteria that works well in the process of both formative and summative evaluation (Kan, 2007). An authentic assessment scale is consistent, fair and clear. It references the appropriate standards. Such an assessment vehicle helps to avoid misunderstandings between teachers, students and parents (Tripp, 2005). Training in this area is essential for teacher candidates.

A major hesitation in teaching media in subject-matter classes is the lack of ability to objectively assess student work in a media format. Many teachers do not have expertise in the film, video, and audio formats. In his book, Assessing Media Work, Chris Worsnop (1997) provides rubrics for assessing multimedia projects. The rubrics break down the five major areas of assessment of such projects, using scales ranging from "Consistently exceeds expectations," to "Consistently meets and may exceed expectations", "Usually meets expectations", "Inconsistently meets expectations", "Inconsistently meets expectations", "Does not meet expectations," and "Not present" (p.25).

In preparing a project, it is important for students to have a clear target. This enables a student to know what is expected by the teacher, and knowing the expectations, may even provide an impetus for a student to work toward a higher grade. It is advantageous for teachers to have a rubric, so they do not fear assigning and assessing student work done in a non-traditional, non-written format. Worsnop selected five areas for assessment of multimedia projects, focusing on specific traits. First, the work is evaluated on the ideas and/or content of the piece. Then it is judged according to its organization and structure. Third, the work is viewed in relation to the student's effective use of language and rhetoric of the project medium. The next level is the use of the student's voice in the piece and the relationship to the target audience. Finally, the piece is assessed according to the student's competence in the handling of technology of the genre selected (Tripp, 2005).

The goal of most students is merely to complete a set of instructions to reach the assignment's end. When the assignment starts with a well-planned rubric, the teaching plan flows from the rubric's objective and the students are reminded of the points, repeatedly. Since the same rubric may be employed to evaluate existing work or teacher models, theoretically the students will learn to recognize quality in their own work. This method separates academic accomplishment from the individual notion of sufficient effort to complete the task. As students become more adept 
using the rubric, they will realize their own strengths and be aware of the skills that need more development and emphasis. This process will also create and develop a greater sense of personal maturity and ownership of their academic products and responsibility for their work habits.

However, technology is branding another definition for comprehension flexing the thoughts of both sides of the teacher's desk. Alternative assessment models may have many faces. Teachers need the structure that a rubric provides to avoid a grade that reflects the 'distraction quotient' of the student product. Without a rubric for a PowerPoint presentation, that technological distraction of a few colors and flying text might boost a student's grade by a whole letter. With a rubric the choice of colors and animated content become elements of design and presentation to be evaluated. The teacher needs to be well-versed in the proper construction of the PowerPoint presentation before it is considered as a student product. With continued use and practice the students who choose a flashy design without considering the nature of the content and the target audience will realize that they chose in error.

The value of a rubric may be determined by its commutative property. Full understanding of the rubric is essential for each student. The rubric needs to become an evaluative tool for the student as well as the teacher. The underlying objective of the rubric is to demonstrate a measurement of quality in a variety of elements contained in a work or project. Pickett, in creating Rubrics for Web Lessons, notes that this involvement empowers the students, and as a result, their learning becomes more focused and self-directed (McAteer, 2005). While grading is usually the purvey of the teacher, the rubric concept is a life skill aiding the individuals to discern elements of quality, not only in their own work, but also to qualify ideas, products and suggestions of other evaluators. This life strategy demands maturity, self-reflection and constant practice.

Multimedia Mania is a contest sponsored by ISTE HyperSig to promote the collaboration of K-12 teachers and students in creating multimedia projects. The judging rubric rates sixteen elements in five different areas: mechanical, multimedia elements, information structure, documentation and quality of content. While this may be workable for a national competition with a staff of judges, it is not a realistic tool for everyday classroom use. In fact, Multimedia Mania provides the student participants with a yes/no checklist version of the rubric. This primer may be a good start, but it does not provide the student with the same evaluative practice afforded by a welldeveloped rubric (http://ced.ncsu.edu/mania/mm docs/2004 judge rubric.html). While the student checklist contains the same elements as the judges' rubric, the yes/no format does not provide the students with the opportunity to examine the quality of their work. Most students work a project to the completion of the teacher's instructions. Most students do not interpret "Check your work" as an actual instruction but simply as the teacher expelling yet another breath.

Consider the element of Screen Design as described by Multimedia Mania. The student checklist simply states, "The combination of multimedia elements (buttons, link, and graphic) and content communicate the intended ideas clearly" (Vasu et. al.). The judges' rubric spells out the definition of screen design in four clear steps. The students with the checklist would respond "yes" because buttons, links, and graphics are present while the students with the rubric would be forced to measure their work against four distinct standards. However, as with many generic rubrics, some requirements seem vague or overlapping. The items listed as mechanical, technical, navigation, spelling and grammar, and completion have a hair-splitting quality that may only apply to a national competition.

\section{CONCLUSION}

Training in the development and utilization of effective rubrics provides a valuable resource for future teachers. It is vital that they have this experience in their teacher preparation courses. The following rubric is an example of a teacher's ongoing assessment process and has been adapted and used with high school students. Although its origin is from a generic rubric, both the elements and the evaluative information have morphed as the teacher's experience has grown with the tool. The six elements are distinctly different and the rating continuum is clear. In the category of Graphical Design, a student will quickly discern the difference between "exaggerated emphases upon graphics" and "multimedia elements add a high level to the content." 
The rubric is an authentic assessment tool used for evaluating criteria that are subjective and complex. It allows the assessment to be consistent, objective, and fair, and clearly shows the students what is expected of their work and how it will be evaluated. It also provides benchmarks which can be used to measure and document student progress. It is very time consuming for a teacher to calibrate a rubric, but its value as a learning tool, as well as a life skill, may be invaluable. Multimedia Project Rubric

\begin{tabular}{|c|c|c|c|c|c|c|}
\hline Assignment: & \multicolumn{3}{|c|}{ Communicate complete information on } & animation. & \multirow[b]{2}{*}{$\begin{array}{c}\text { Self } \\
\text { Evaluation }\end{array}$} & \multirow[b]{2}{*}{$\begin{array}{c}\text { Teacher } \\
\text { Evaluation }\end{array}$} \\
\hline Points & 1 & 2 & 3 & 4 & & \\
\hline Topic/Content & $\begin{array}{l}\text { Most information is } \\
\text { confusing, incorrect or } \\
\text { incomplete }\end{array}$ & $\begin{array}{l}\text { Some essential } \\
\text { information is confusing, } \\
\text { incorrect or incomplete }\end{array}$ & $\begin{array}{l}\text { Information is clear, } \\
\text { appropriate and correct. }\end{array}$ & $\begin{array}{l}\text { Covers topic completely and in } \\
\text { depth. Information is clear, } \\
\text { appropriate, and correct. }\end{array}$ & & \\
\hline $\begin{array}{l}\text { Organization of } \\
\text { Content }\end{array}$ & No logical sequence & $\begin{array}{l}\text { Some logical sequence but } \\
\text { path is confusing }\end{array}$ & $\begin{array}{l}\text { Logical sequencing; paths } \\
\text { to more information are } \\
\text { clear }\end{array}$ & $\begin{array}{l}\text { Logical sequencing, path to all } \\
\text { information is clear and concise }\end{array}$ & & \\
\hline Graphical Design & $\begin{array}{l}\text { Exaggerated emphasis } \\
\text { upon graphics and special } \\
\text { effects; screens are } \\
\text { confusing and cluttered }\end{array}$ & $\begin{array}{l}\text { Graphical elements do not } \\
\text { reinforce content; some } \\
\text { tendency toward random } \\
\text { use of graphics and special } \\
\text { effects. }\end{array}$ & $\begin{array}{l}\text { Design elements and } \\
\text { content combine } \\
\text { effectively and reinforce } \\
\text { each other. }\end{array}$ & $\begin{array}{l}\text { Multimedia elements add a high } \\
\text { level to the content }\end{array}$ & & \\
\hline Mechanics & $\begin{array}{l}\text { Includes } 4 \text { or more } \\
\text { spelling errors and/or } \\
\text { grammatical errors }\end{array}$ & $\begin{array}{l}\text { Includes } 2-3 \text { spelling } \\
\text { errors and/or grammatical } \\
\text { errors }\end{array}$ & $\begin{array}{l}\text { Includes 1-2 spelling } \\
\text { errors and/or grammatical } \\
\text { errors }\end{array}$ & $\begin{array}{l}\text { Has no spelling errors or } \\
\text { grammatical errors }\end{array}$ & & \\
\hline $\begin{array}{l}\text { Technical } \\
\text { Requirements }\end{array}$ & $\begin{array}{l}\text { Includes too few or too } \\
\text { many slides, no graphics } \\
\text { or animation }\end{array}$ & $\begin{array}{l}\text { Contains appropriate } \\
\text { number of slides, limited } \\
\text { graphics and other } \\
\text { enhancements }\end{array}$ & $\begin{array}{l}\text { Contains appropriate } \\
\text { number of slides, some } \\
\text { advanced features }\end{array}$ & $\begin{array}{l}\text { Contains several advanced features } \\
\text { such as animation, video, audio } \\
\text { which are effectively used }\end{array}$ & & \\
\hline $\begin{array}{l}\text { Presentation } \\
\text { Skills }\end{array}$ & $\begin{array}{l}\text { Great difficulty } \\
\text { communicating ideas due } \\
\text { to lack of preparation or } \\
\text { incomplete work. }\end{array}$ & $\begin{array}{l}\text { Some difficulty } \\
\text { communicating ideas due } \\
\text { to lack of preparation or } \\
\text { incomplete work. }\end{array}$ & $\begin{array}{l}\text { Communicates ideas } \\
\text { clearly, shows adequate } \\
\text { preparation. }\end{array}$ & $\begin{array}{l}\text { Communicates ideas with } \\
\text { enthusiasm, excellent preparation } \\
\text { and clear delivery. }\end{array}$ & & \\
\hline $20-24 \mathrm{E}$ & gert (A) 15-19 Above Ave & 10-14 Average $(\mathrm{C})$ & 6-9 Below Average (D) & Total Points & & \\
\hline
\end{tabular}




\section{AUTHOR INFORMATION}

Carol M. Shepherd, Ed.D., is an Associate Professor in the College of Education at National University, at the Sacramento, California campus. She teaches courses in educational psychology as well as best practices and research methods, and has published a number of articles on differentiated learning and instruction. She provides rubrics in her courses, and has found that students achieve significantly greater learning when provided with them.

Ann Mary Mullane, MA, is an Instructor at Essex County College in West Caldwell, New Jersey. She teaches courses in study skills and computer technology, and has published a number of articles dealing with evaluation and assessment of student learning. In addition, she is a published playwright, and a number of her plays have been produced for the public.

\section{REFERENCES}

1. Becker, H. (1993, May). Teaching with and about computers in secondary schools. Association for Computing Machinery. Communications of the ACM. 36(5), 69-73.

2. Berry, B. (1997, Spring). New ways of testing and grading can help students learn and teachers teach. Reforming Middle Schools and School Systems: Changing School in Long Beach, 1(2). Retrieved September 20, 2005 from http://www.middleweb.com/CSLB2testing.html

3. Gardner, H. (1995, November). Reflections on multiple intelligences: Myths and messages. Phi Delta Kappan, 77(3), 200-208.

4. Gardner, H. (1995, December). "Multiple intelligences" as a catalyst. English Journal (High School Edition), 84(8), 16-19.

5. Jancich, H. (Project Director). (n.d.). Are your teachers teaching effectively with technology? [PowerPoint presentation]. MyTarget2. Retrieved October 3, 2005 from http://mytarget.iassessment.org/

6. Kan, A. (2007, January). An alternative method in the new educational program from the point of performance-based assessment: Rubric scoring scales. Kuram ve Uygulamada Egitim Bilimleri, 7(1), 144153. Retrieved February 2, 2008 from ProQuest database.

7. Lane, S. (2004, Fall). Validity of high-stakes assessment: Are students engaged in complex thinking? Education Measurement, Issues and Practice, 23(3), 6-15.

8. McAteer, E. (2005, August). Assessment Portfolio: a compilation of standardized tests and assessments for evaluating high school students in English language arts. Unpublished portfolio. National University, California.

9. Mitchell, A. (2006, May/June). Introduction to rubrics: An assessment tool to save grading time, convey effective feedback and promote student learning. Journal of College Student Development, 47(3), 352-356.

10. Pickett, N. (2001, June). Rubrics for Web Lessons. Retrieved August 20, 2005 from the SDSU website: http://edweb.sdsu.edu/webquest/rubrics/weblessons.htm

11. Sefton-Green, J. \& Sinker, R. (2000). Evaluating Creativity. London: Routledge.

12. Tripp, L. (2005). Workshop Report: How to do assessment and evaluation in media literacy. Center for Media Literacy. Retrieved September 6, 2005, from http://www.medialit.org/reading_room/article18.html

13. Vasu, E., Stedman, J., Lambert, J., \& Bean, E. (Multimedia Mania Team). (n.d.). Multimedia Mania Student Checklist. MidLink Magazine. Retrieved October 6, 2005 from http://www.ncsu.edu/midlink/

14. Worsnop, Chris. (1997). Assessing Media Work. Mississauga, Canada: Wright Communications. 